\title{
Analysing Effect of Direction of Layups to Distortions of Laminated Carbon Fibre- Reinforced Composites
}

\author{
Dharu Feby Smaradhana ${ }^{1}$ \\ ${ }^{1}$ Mechanical Engineering Department, Universitas Sebelas Maret \\ e-mail address : dharufs@staff.uns.ac.id
}

\section{Keywords:}

Channel warping, laminate, layups, distortion, spring back

\begin{abstract}
:
The distortions of the laminates (flat panels and channel sections) with different stacking sequences were investigated in this lab session. There were two methods compared, measurement of the experimental specimens and prediction using classical laminate theory. The experimental results showed that the specimens with layup $\left(90,0_{3}\right)$ and $\left(0_{3}, 90\right)$ had the largest curvature. The spring forward/back angles of the measurement was higher than those of the prediction though the trends of the distortions of the channel and the flat specimens were almost similar. There were several factors affecting distortions such as the tool thermal expansion, chemical shrinkage, the arrangement of vacuum bag and edge effects.
\end{abstract}

\section{INTRODUCTION}

Residual stresses of fibre reinforced plastic composites, especially, carbon fibre reinforced plastic/epoxy (CFRP), are such an unavoidable phenomenon during the curing process in autoclave. This phenomenon is caused by thermal expansion between the fibres and matrix [1] and shrinkage of resin such as epoxy [2] which may introduce the distortions of the cured laminate composites [1][3]. According to Carolyne Albert and Goran Fernlund [1], the distortions are usually classified into two, warpage - curving of flat panels - and spring forward (for a reduction) or back (for an increase of enclosed angles of angled sections) in simple $\mathrm{U}, \mathrm{C}$ or $\mathrm{L}$ geometries. In addition, the arrangement of the plies (symmetry, asymmetry, balance, or unbalance) shall be taken into account once investigating the distortions of the laminates section.

The aim of this report was to compare the distortions of the experimental results using CAD software to those of the predicted results based on the classical laminate theory using Laminate Analysis Programme (LAP). There were five specimens made of CFRP prepreg with different stacking sequences for each section (flat and channel sections) (total ten) inspected. The factors influencing distortions were also investigated to reveal the conclusions and suggestions for further works.

\section{EXPERIMENTAL DETAILS}

\subsection{Specimens}

The specimens were made of carbon fibre reinforced epoxy which were prepregs, so-called T300-914 as shown in figure 1. Additionally, the thickness of one ply was $0.125 \mathrm{~mm}$. There were ten specimens provided (five for each sections). The details regarding the stacking sequences are depicted in table 1 .

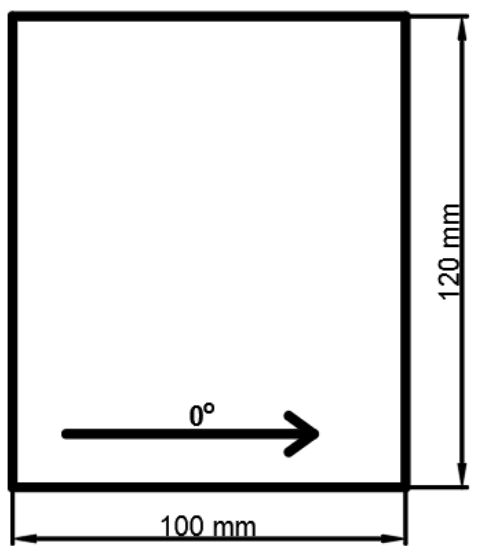

Figure 1. Dimensions of specimen

https://dx.doi.org/10.20961/mekanika.v19i1.40960

Submitted March 2020; Revised March 2020; Published March 2020

(C) Mekanika: Majalah Ilmiah Mekanika. All right reserved. 
Table 1. Stacking Sequences

\begin{tabular}{|c|c|}
\hline Specimens & Layup \\
\hline F1 and C1 & $\left(90 / 0_{3}\right)$ \\
\hline F2 and C2 & $\left(0_{3} / 90\right)$ \\
\hline F3 and C3 & $\left(90_{2} / 0_{2}\right)$ \\
\hline F4 and C4 & $(90 / 0)_{2}$ \\
\hline F5 and C5 & $(90 / 0) \mathrm{s}$ \\
\hline
\end{tabular}

*F: Flat; C: Channel

There was no balanced laminate - a laminate in which all equal-thickness plies at angle $\theta$ have the pairs in the opposite direction $(-\theta)$ other than 0 and 90, for example, +45 and -45 [4] examined in this lab session. F1-F4 and C1-C4 can be called as unbalanced asymmetric laminate while F5 and C5 were the only symmetric laminates - laminate that is symmetric in both geometry and material properties with regard to the middle surface [4].

For the channel section, $0^{\circ}$ fibre direction was along the channel axis, and $90^{\circ}$ fibre direction was around the channel cross-section. The stacking sequences were from outside to inside on the mould so that the last ply in the layup sequence was adjacent to the mould surface.

\subsection{Mould}

The mould for channel section used was male mould with $U$ cross-section and two fillets on the top corner with different radius and was made of aluminium. The details of the mould are represented in figure 2 .

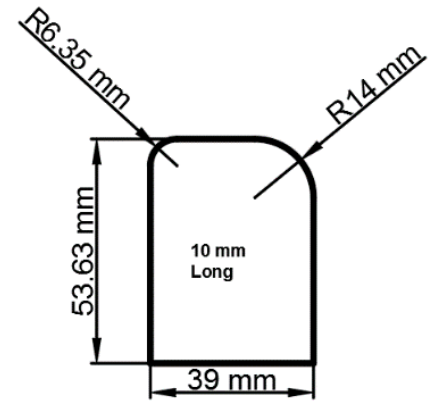

Figure 2. The mould cross-section

The mould's fillet radii were equivalent to the interior profile of four plies channel. The channel section had the nominal fillet radii of 6.5 and 14.5 $\mathrm{mm}$.

\subsection{Manufacturing process}

For flat sections, the plies were oriented as the proposed stacking sequences, then put on the flat mould that had been covered by peel ply. Furthermore, the mould was covered by peel ply and a perforated plastic consecutively as shown in figure 3. For the channel sections, the aluminium male mould was covered by a perforated plastic film and peel ply before the plies were lied as the required stacking sequences. The mould was then covered by peel ply followed by a perforated film. Afterwards, the moulds (both channel and flat section) were put under vacuum before curing process.

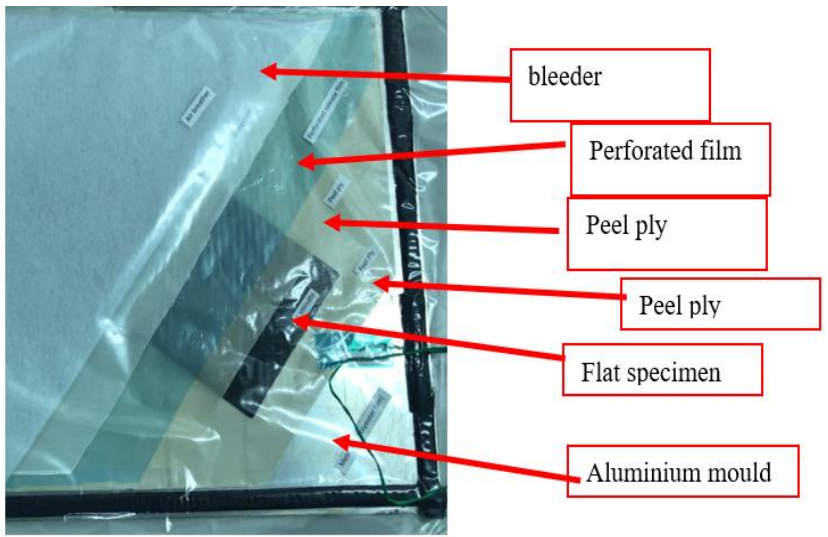

Figure 3. Autoclave preparation

In the curing process, an autoclave was used to cure the specimens with a cure temperature of $175^{\circ} \mathrm{C}$, a pressure of $689.4 \mathrm{kN} / \mathrm{m}^{2}$ (100 Psi) and a heating rate $3^{\circ} \mathrm{C} \mathrm{min}^{-1}$. The specimens were then cooled in the autoclave with temperature of $60^{\circ} \mathrm{C}$ before put on the room temperature of $20^{\circ} \mathrm{C}$.

\subsection{Measurement of Angle}

Both ends of the distorted specimens were scanned, then the results were inserted in AUTOCAD software to be measured without changing the ratio (actual size of the scanned specimens in $\mathrm{mm}$ ).

In the scan results (see figure 4), it is seen that all parts of the channel specimens were distorted. So, the use of circle to determine the radius of curved shape was needed. Figure 5 
illustrates the method to measure the radii of the distorted shapes of the walls and the base.

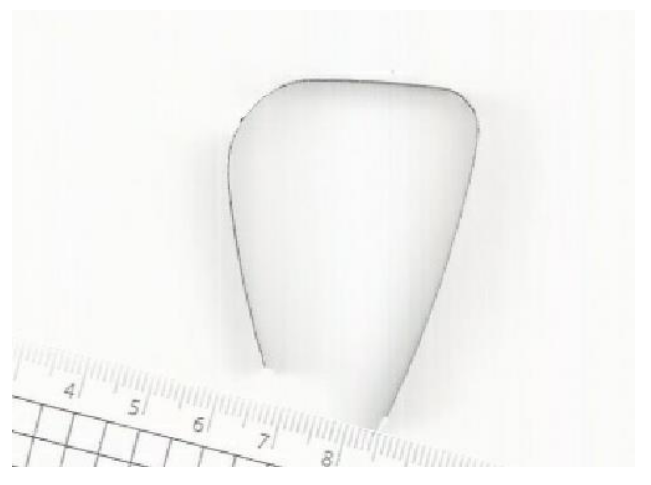

Figure 4. The deformed profile

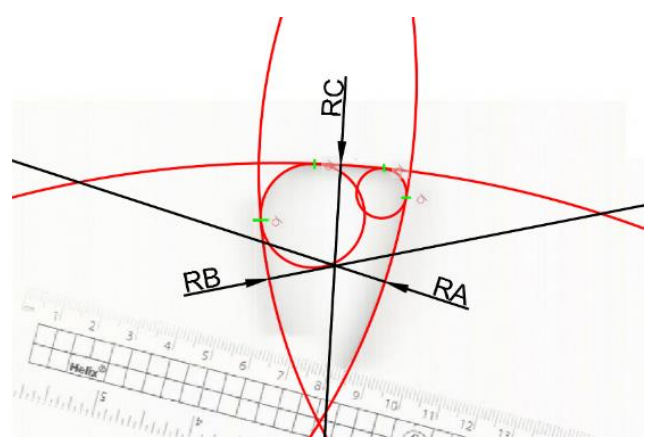

Figure 5. Measurement process

There were five circles made in this method. The first circle was drawn on the one of the wall sections. Afterwards, the second circle was determined for the one of the radii and was tangent to the first circle. The following circles were drawn in the same way consecutively and should be ensured that those were tangent to previous circle as well. In AUTOCAD software, the use of 'parametric tools' is useful to ensure the circle is tangent to another circle automatically (green line). By determining five circles, the radius of two walls and the base of the channel sections could be determined (RA, RB and RC respectively).

\subsection{Curvature}

After the radii of the walls and the base were obtained, the equation 1 was used to calculate the curvature of those sections

$$
K=\frac{1}{R}
$$

$\mathrm{K}=$ Curvature $(1 / \mathrm{mm})$

$\mathrm{R}=$ The radius of distorted section $(\mathrm{mm})$

The curvature obtained was presented in the next section followed by the predicted value in order to be compared

\section{RESULTS}

\subsection{Channel Section}

The distortions in angled section after curing process are called spring forward/back. Spring forward is a reduction of enclosed angles while spring back is an increase of enclosed angles (1). Figure 8 illustrates the difference of spring forward and back.

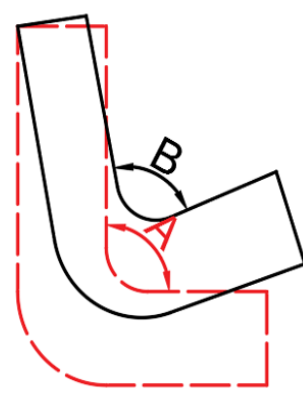

(a)

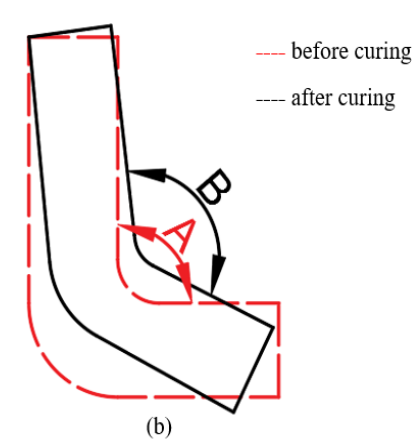

Figure 6. Spring forward (a) and back (b) at angled sections

By visual inspection, the distortions of channel sections could be deduced whether it is spring forward or back. Table 2 represents the distortions of angled sections of channel samples.

Table 2. Channel section curvature

\begin{tabular}{|c|r|c|c|}
\hline Specimens & Picture & Distortions & $\begin{array}{c}\text { Walls' } \\
\text { curvature }\end{array}$ \\
\hline C1 & & $\begin{array}{c}\text { Spring } \\
\text { forward }\end{array}$ & Convex/ \\
negative
\end{tabular}




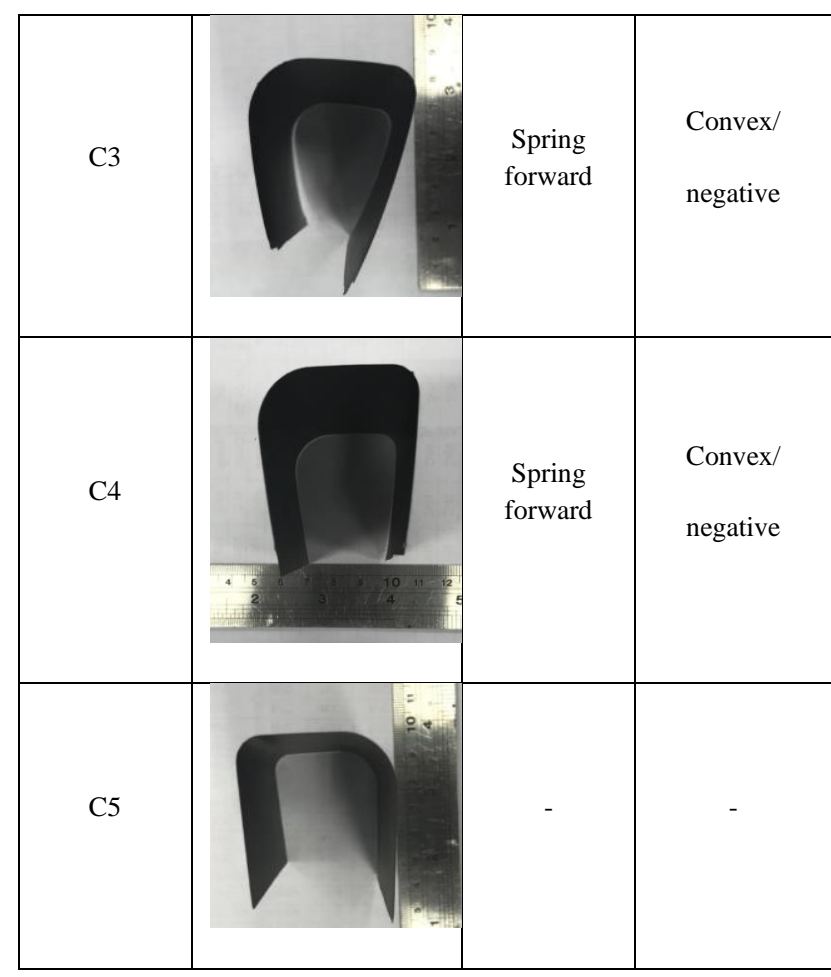

In the table 2, it is clearly seen that spring back was only experienced by $\mathrm{C} 2$ with layup $\left(0_{3}, 90\right)$. On the other hand, the distortions of C5 were difficult to determine by visual observation in which the use of CAD software was needed to examine the types of distortion described in section 5 .

\subsection{Flat Section}

Warpage, so-called curvature, is a distortion that occur in the flat sections, the walls and the base of channel sections [1]. The magnitude of curvature is determined based on the mid-plane of the laminates. There are two types of curvature which are positive and negative curvatures, socalled concave and convex curvatures respectively. Figure 5 illustrates the difference of concave and convex curvatures.
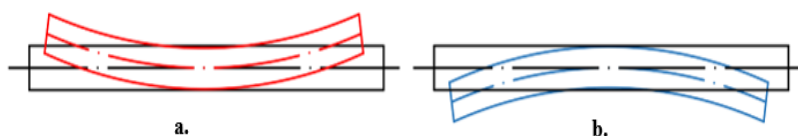

Figure 7. Concave (positive)(a)(--) and convex (negative)(b)(--) curvatures

Regarding the way to determine the curvature axis, two axes $-\mathrm{x}$ and $\mathrm{y}-$ were used for flat sections while only was y axis used in the channel sections since the curvature in $\mathrm{x}$ axis was small and assumed to be negligible (locked by the mould). Figure 6 shows how to determine the curvature axis whether it is $\mathrm{x}$ or $\mathrm{y}$ in flat sections.
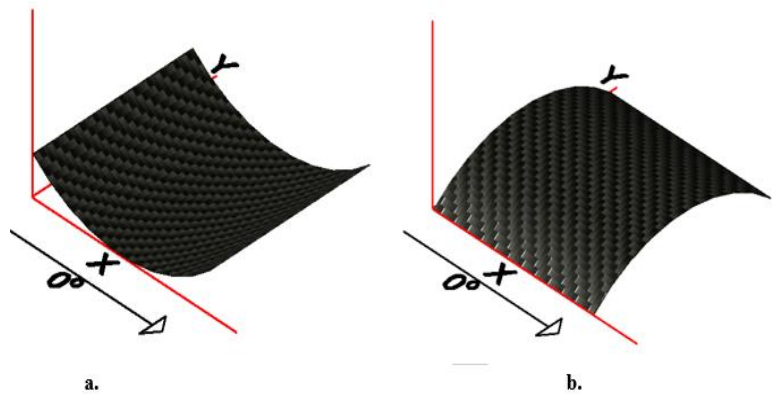

Figure 8 . The curvature axis, the curvature in the $x-$ direction (a) and the curvature in the $y$-direction

By visual inspection, the magnitude of curvature could be assessed roughly. Table 3 shows the curvature of flat specimens after curing.

Table 3: Flat sections curvature

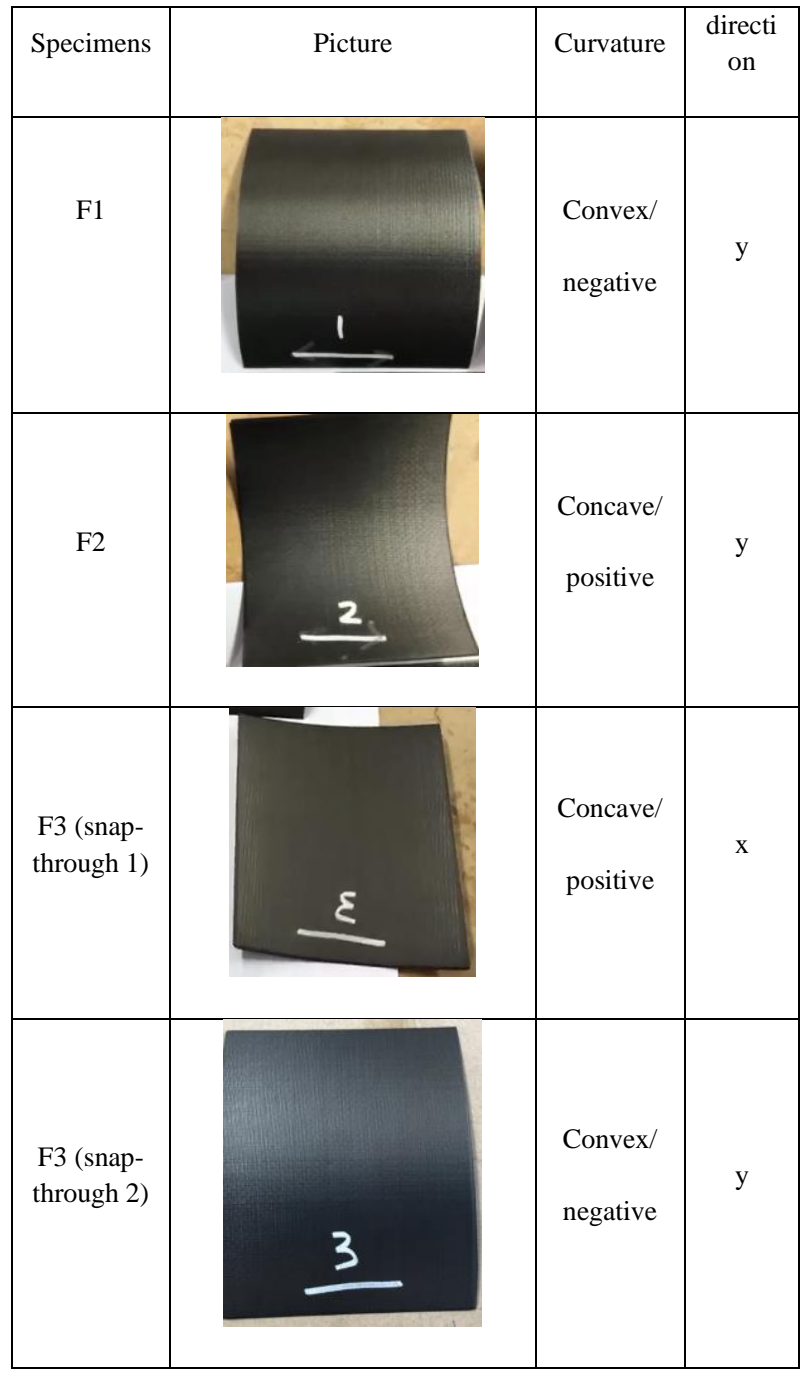




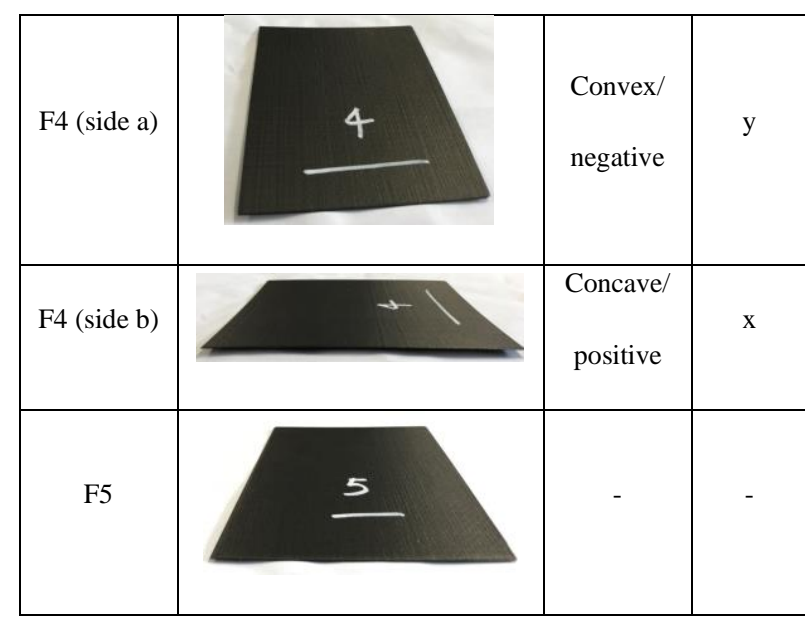

In table 3, it is clear that F1 and F2 had the largest curvature. Those curvatures occurred in the $\mathrm{y}$-axis but with different types of curvature in which F1 had convex (negative) curvature and F2 concave (positive) curvature. Moreover, F3 was the only specimen that exhibited snap-through behaviour - laminate having two stable equilibrium [6]. This panel had positive curvature in the $\mathrm{x}$-axis and the negative curvature in the $\mathrm{y}$ axis. For F4, the curvature occurring was so small and existed both in the $\mathrm{x}$ and $\mathrm{y}$ directions, so called unstable saddle configuration [6]. There was no curvature seen in F5 by visual inspection.

\subsection{Curvature}

Curvature of flat sections is shown in table 4 with the highest distortions obtained by F2. Meanwhile, curvature of channel section is presented in table 5. It is quite clear that the highest distortion was obtained by $\mathrm{C} 1$ with layups of $\left(90 / 0_{3}\right)$. This curvature was obtained after using equation (1).
Table 4. Curvature of flat sections

\begin{tabular}{|c|r|r|}
\hline Specimens & $\begin{array}{c}\Delta \mathrm{ky} \\
(1 / \mathrm{mm})\end{array}$ & $\begin{array}{c}\Delta \mathrm{kx} \\
(1 / \mathrm{mm})\end{array}$ \\
\hline $\mathrm{F} 1$ & -0.01362 & 0 \\
\hline $\mathrm{F} 2$ & 0.01414 & 0 \\
\hline F3(snap-through) & -0.00558 & 0.00632 \\
\hline F4 & -0.00105 & 0.00051 \\
\hline F5 & -0.00023 & 0.00013 \\
\hline \multicolumn{2}{|c}{}
\end{tabular}

\section{DISCUSSION}

The distortion of the laminate composites can be affected by the mould used [1][7] and the vacuum bag arrangement [8]. Both factors may induce warpage in laminate during the curing process.

The arrangement of vacuum bag used is shown in figure 3 with the top bleeder used to minimise the distance resin that should be transported within the laminate [8]. Nevertheless, this method might still evoke resin rich area at the bottom of laminate close to the mould due to the surface tension between the tooling and the resin and could lead to convex curvature [8].

On the one hand, the thermal expansion of the aluminium mould could also cause the distortions due to its coefficient thermal expansion (CTE) higher than the specimens' CTE. The mould expansion, because of the change of the temperature during the curing process, might stretch the laminate, but once cooling, the tool might shrink more than the cured laminate. This phenomenon could also evoke complex stress situation in a laminate component, especially in the corner radii for channel sections that caused irreversible deformation, then contributed to the

Table 4. Curvature of channel sections

\begin{tabular}{|c|c|c|c|c|c|c|c|c|c|c|c|c|c|}
\hline \multirow[b]{3}{*}{ Specimen } & \multirow[b]{3}{*}{ Layup } & \multicolumn{9}{|c|}{ Radius (mm) } & \multirow{2}{*}{\multicolumn{3}{|c|}{ Curvature (Ky) (1/mm) }} \\
\hline & & \multicolumn{3}{|c|}{ End A } & \multicolumn{3}{|c|}{ End B } & \multicolumn{3}{|c|}{ Average } & & & \\
\hline & & \begin{tabular}{|l|} 
side 1 \\
\end{tabular} & side 2 & base (top) & side 1 & side 2 & base (top) & side 1 & side 2 & base (Top) & side 1 & side 2 & base (Top) \\
\hline $\mathrm{Cl}$ & $(90 / 03)$ & 80.5 & 69.91 & 70.993 & 77.727 & 67.099 & 63.085 & 79.1135 & 68.5045 & 67.039 & -0.01264 & -0.01460 & -0.01492 \\
\hline $\mathrm{C} 2$ & $(03 / 90)$ & 82.34 & 79.789 & 65.021 & 84.819 & 79.651 & 75.364 & 83.5795 & 79.72 & 70.1925 & 0.01196 & 0.01254 & 0.01425 \\
\hline $\mathrm{C} 3$ & $(902 / 02)$ & 141.357 & 165.518 & 269.68 & 108.768 & 161.668 & 102.002 & 125.0625 & 163.593 & 185.841 & -0.00800 & -0.00611 & -0.00538 \\
\hline $\mathrm{C} 4$ & $(90 / 0) 2$ & 450.675 & 342.079 & 364.822 & 318.351 & 320.714 & 345.673 & 384.513 & 331.3965 & 355.2475 & -0.00260 & -0.00302 & -0.00281 \\
\hline $\mathrm{C} 5$ & $(90 / 0) \mathrm{s}$ & 625.858 & 1440.7 & 716.817 & 3583.42 & 2056.998 & 779.4 & 2104.641 & 1748.847 & 748.1085 & -0.00048 & -0.00057 & -0.00134 \\
\hline
\end{tabular}


spring forward/back [9]. It was thought that the lower coefficient thermal expansion (CTE) of the mould used led to the smaller the distortions occurring [9].

The tool surface condition also contributed to the distortions of the laminates in which according to Carolyne Albert and Goran Fernlund [1], the mould with proper surface finish was proven to give lower spring forward/back effect to the channel sections than the mould without surface finish.

On the one hand, it is unquestionable that stacking sequence is one of the major effects causing the distortions in laminate. It can be seen in the previous section that most specimens both flat and channel sections exhibited distortions, either large or small distortions, except specimens that had symmetric layup (F5 and C5).

According to Jones [4], CTE and elastic properties vary in laminates. Thus, by introducing the symmetric laminates, those various properties from one ply can be countered by the reflected ply, so the distortions can be minimized. Furthermore, per classical laminate theory, the symmetric laminate also makes bending-extension coupling stiffness (Bij) become zero. However, once laminates were asymmetric like F1-F4 and C1-C4 specimens, these laminates would not be able to deal with the differential contractions during cooldown which could evoke coupling of forces and residual stresses.

\section{CONCLUSION}

Analysing the effect of layups to the distortions of CFRP laminate had been conducted. The experimental results showed that the specimens with layup $\left(90,0_{3}\right)$ and $\left(0_{3}, 90\right)$ had the largest curvature. The spring forward/back angles of the measurement was higher than those of the prediction though the trends of the distortions of the channel and the flat specimens were almost similar. There were several factors affecting distortions such as the tool thermal expansion, chemical shrinkage, the arrangement of vacuum bag and edge effects.

\section{REFERENCES}

1. C. Albert and G. Fernlund, "Spring-in and warpage of angled composite laminates," Compos. Sci. Technol., vol. 62, no. 14, pp. 1895-1912, 2002.

2. C. Outline, "Chapter 2 Warpage of Large Curved Composite Panels,” pp. 3-59.

3. J. L. O. and D. Lemoine, "Experimental study of spring forward in cured laminated Uchannels made from unidirectionally reinforced carbon fibre-epoxy prepregs," 1998.

4. R. M. Jones, "Mechanics of composite materials," 2nd ed. London: Taylor \& Francis, 1999.

5. C. Buchmann, S. Langer, J. Filsinger, and K. Drechsler, "Analysis of the removal of peel ply from CFRP surfaces," Compos. Part B Eng., vol. 89, pp. 352-361, 2016.

6. M. L. Dano and M. W. Hyer, "Snap-through of unsymmetric fiber-reinforced composite laminates," Int. J. Solids Struct., vol. 39, no. 1, pp. 175-198, 2001.

7. S. Pagliuso, "Warpage, a nightmare for composite parts producers.pdf." ICCM-IV, Tokyo, 1982.

8. D. W. RADFORD, "Cure shrinkage induced warpage in flat uni-axial composites," Journal of composites technology \& research, vol. 15, no. 4. pp. 290-296, 1993.

9. H. W. Wiersma, L. J. B. Peeters, and R. Akkerman, "Prediction of springforward in continuous-fibre/polymer L-shaped parts," Compos. Part A Appl. Sci. Manuf., vol. 29, no. 11, pp. 1333-1342, 1998. 